20

\title{
Искусственные электрон-транспортные цепи на основе зеленого флуоресцентного белка*
}

\author{
(C) А.М. Богданов, А.В. Мамонтова, А.В. Тительмаер, К.А. Лукьянов, А.С. Мишин \\ Институт биоорганической химии им. академиков М.М. Шемякина и Ю.А. Овчинникова РАН, \\ 117997 Москва, Россия \\ ฯ e-mail: mishin@ibch.ru
}

Поступила в редакцию 24.09.2018 г.

Фотоиндуцируемый донор электронов - улучшенный зеленый флуоресцентный белок (EGFP) - соединен с окислителями белковой природы в составе химерной полипептидной цепи. Сравнение фотостабильности EGFP и химерных белков как в отсутствие, так и в присутствии не связанных с белками окислителей в растворе показало работоспособность созданных модельных электрон-транспортных цепей.

DOI: $10.21883 / \mathrm{OS} .2019 .01 .47062 .265-18$

\section{Введение}

Окислительная фотоконверсия флуоресцентных белков [1] является фотохимической реакцией, в которой в присутствии внешних окислителей некоторые зеленые флуоресцентные белки (прежде всего EGFP) выступают в качестве доноров электронов. При этом хромофор зеленого флуоресцентного белка окисляется и переходит в форму, флуоресцирующую в красной области спектра. С момента своего открытия это явление привлекло интерес многих биофизиков и специалистов по квантовой химии $[2-8]$, поскольку механизм окислительновосстановительной реакции между хромофором, защищенным бета-бочонком флуоресцентного белка, и внешними окислителями, в том числе белковой природы, был совершенно неясен. Наиболее убедительным на сегодняшний день выглядит объяснение, включающее целую цепочку участников, которая начинается с первичного акцептора электрона - боковой цепи остатка тирозина [6], находящегося в непосредственном контакте с хромофором. Появление красной флуоресценции это лишь второй и, по-видимому, необязательный этап окислительной фотоконверсии. Первичным проявлением процесса окислительной фотоконверсии является исчезновение зеленой флуоресценции. Как было показано в многочисленных работах [9-11], окислительная фотоконверсия является одним из основных путей, приводящих к необратимому фотообесцвечиванию зеленых флуоресцентных белков при микроскопии живых клеток за счет реакции с редокс-активными молекулами как внутриклеточными, так и добавленными в питательные среды (прежде всего рибофлавином и пиридоксальфосфатом [9-11]).

В первых описанных экспериментах эффективная фотоконверсия EGFP наблюдалась в присутствии многократного избытка окислителей ( $1 \mathrm{mM}$ окислителя,

* XIII International Conference on Hole Burning, Single Molecule, and Related Spectroscopies: Science and Applications (HBSM-2018), August 6-12, 2018, Suzdal-Moscow, Russia. $\sim 1 \mu \mathrm{M}$ EGFP) - феррицианида калия, бензохинона, цитохрома $c$. Перечисленные окислители являются одноэлектронными и, по-видимому, такой избыток необходим для прохождения фотоконверсии до стадии образования формы с красной флуоресценцией [1]. Следует отметить, что фотообесцвечивание зеленой формы заметно усиливалось при значительно меньших концентрациях окислителей. Так, уже при концентрации $10 \mu \mathrm{M}$ феррицианида калия фотообесцвечивание происходит заметно быстрее, чем в его отсутствие [1].

В настоящей работе с помощью генной инженерии объединили восстановитель (EGFP) и окислитель белковой природы в составе одного химерного белка и сравнили фотообесцвечивание зеленой формы EGFP в различных условиях, в том числе в присутствии дополнительных внешних окислителей. Скорость фотообесцвечивания служила, таким образом, критерием эффективности протекания светоиндуцированного переноса электрона в исследуемых белках.

\section{Методика эксперимента}

\section{Генетические конструкции}

Генноинженерные конструкции pQE-FE, pQE-EF, pQE-R2E，pQE-ER2，pQE-EM，pQE-BE， кодирующие химерные белки флаводоксин-EGFP, EGFP-флаводоксин, малая субъединица рибонуклеотид-редуктазы (R2)EGFP, EGFP-малая субъединица рибонуклеотид-редуктазы (R2), EGFP-моноаминоксидаза A, EGFP-синий флуоресцентный белок бактерии Vibrio fischeri (vfBFP), были созданы на основе экспрессионного вектора pQE30. Отдельные части химерных белков соединены линкером из 12 аминокислот (GHGTGSTGSGSS).

\section{Экспрессия и выделение белков}

Для экспрессии химерных конструкций был использован вектор pQE30 (Qiagen), содержащий в одной рамке считывания с генами целевых белков на 5'-конце 


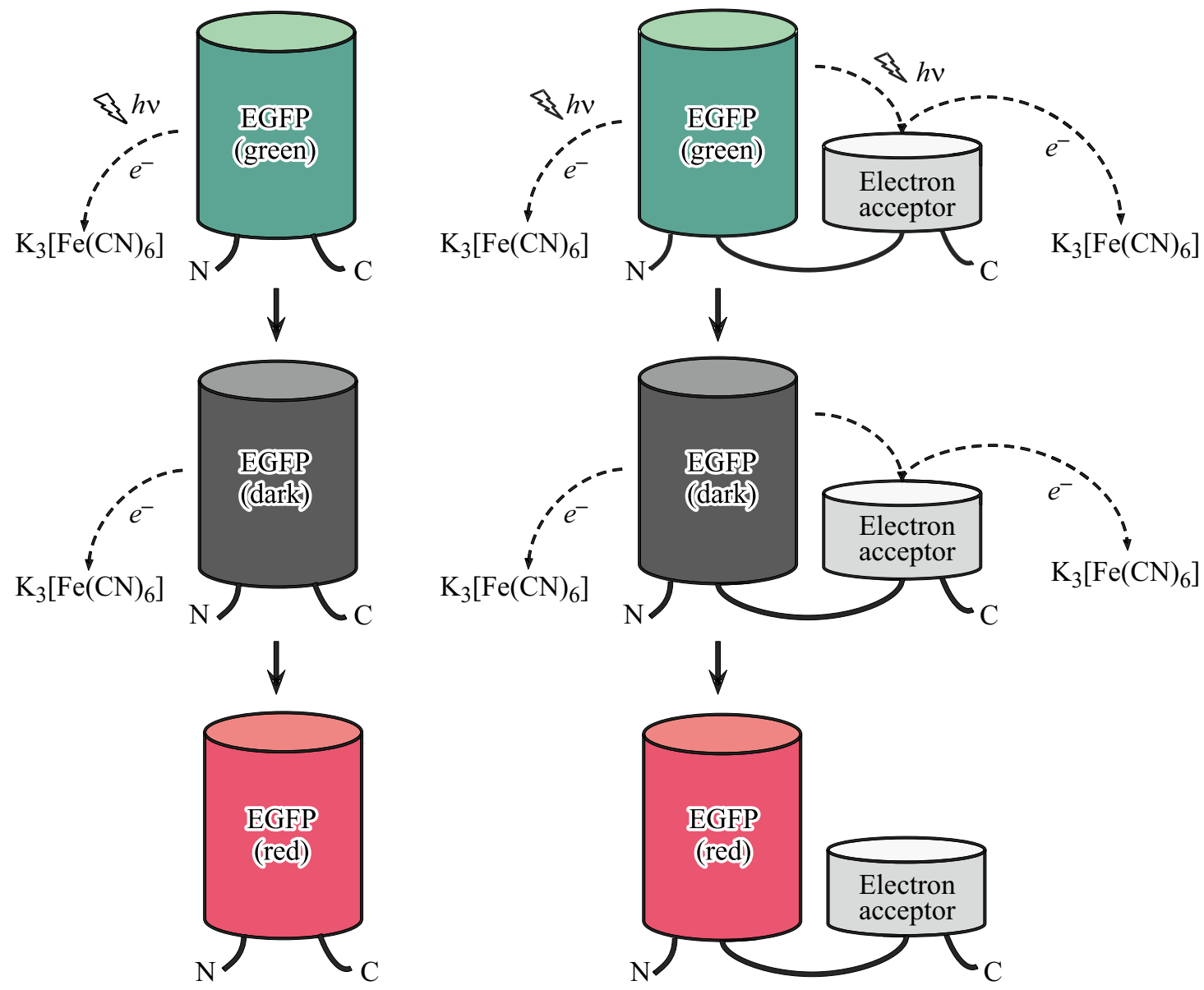

Рис. 1. Схема искусственных электрон-транспортных цепей на основе флуоресцентного белка ЕGFP и редокс-активных белков. Зеленый флуоресцентный белок под воздействием синего света $(\sim 470 \mathrm{~nm})$ способен передавать электрон на молекулу-окислитель в растворе (левая колонка) и/или на молекулу-окислитель в составе той же полипептидной цепи (правая колонка), при этом зеленая флуоресценция исчезает. Образование хромофора с красной флуоресценцией требует еще одной стадии окисления.

последовательность, кодирующую 6 гистидинов. Гексагистидиловая последовательность используется для очистки белков методом аффинной хроматографии. Соответствующими генно-инженерными конструкциями трансформировали компетентные клетки $E$. coli штамма XL-1Blue. Бактериальную культуру инкубировали в питательной среде LB при термостатировании $\left(37^{\circ} \mathrm{C}\right)$ и покачивании в течение ночи. Далее клетки разрушали с помощью ультразвукового дезинтегратора 60 Sonic Dismembrator (Fisher Scientific), а осветленный клеточный лизат, содержащий целевые белки, смешивали с металлоаффинной смолой Talon (Clontech). Аффинную хроматографию проводили в соответствии с рекомендациями производителя.

\section{Микроскопия и измерение фотостабильности}

Для микроскопии использовалась система Leica AF6000LX, основанная на инвертированном микроскопе DMI 6000 B, оборудованном иммерсионным масляным объективом HCX PL APO lbd. BL 63 × 14NA, цифровым ПЗС-регистратором Photometrics CoolSNAP HQ и ртут- ной лампой 120W HXP (Osram) в качестве источника света. Сигналы зеленой и красной флуоресценции детектировались с помощью стандартного набора светофильтров GFP (возбуждение ВР470/40, эмиссия ВР525/50). Измерение фотообесцвечивания включало в себя следующие стадии, повторяющиеся циклически: регистрацию зеленой флуоресценции (слабое облучение) и обесцвечивание (интенсивное облучение удельной мощностью около $\left.0.5-10 \mathrm{~W} / \mathrm{cm}^{2}\right)$. Количество циклов подбирали таким образом, чтобы интенсивность флуоресценции в конечном счете снижалась чуть больше, чем на 50\%.

\section{Результаты и их обсуждение}

Химерные белки, объединяющие молекулу светоиндуцируемого восстановителя (EGFP) и окислителя можно рассматривать как элементарную электрон-транспортную цепь (рис. 1). При этом наряду с окислительной фотоконверсией EGFP с участием внешних окислителей, доступность которых вблизи молекулы белка ограничена диффузией, становится возможен альтернативный 

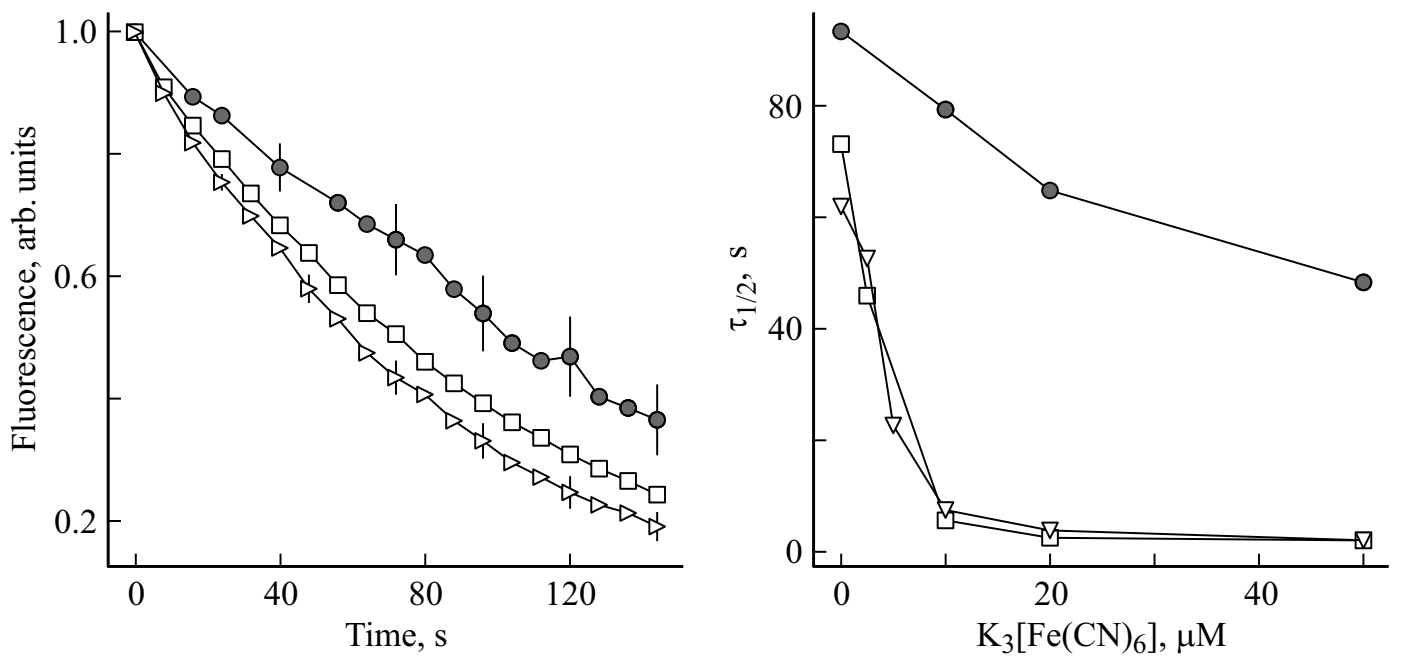

Рис. 2. Фотостабильность химерных белков (одноэлектронные окислители). Слева: кинетика фотообесцвечивания зеленого флуоресцентного белка EGFP (серые круги) и химерных белков EGFP-флаводоксин (квадраты), EGFP-малая субъединица бактериальной рибонуклеотид редуктазы (треугольники), вертикальные линии показывают стандартное отклонение сигнала; справа: зависимость времени полуобесцвечивания от концентрации окислителя в растворе.
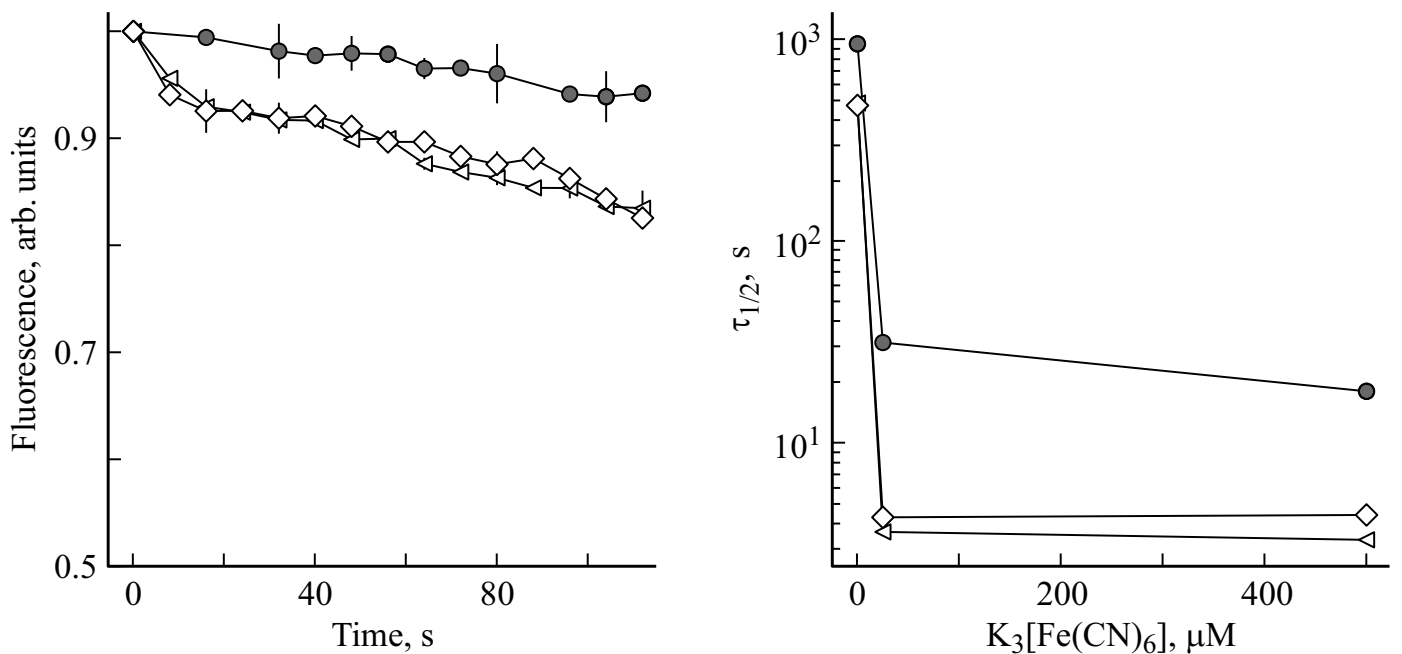

Рис. 3. Фотостабильность химерных белков (двухэлектронные окислители). Слева: кинетика фотообесцвечивания зеленого флуоресцентного белка EGFP (серые круги), EGFP-vfBFP (ромбы), EGFP-моноаминоксидаза А (треугольники). Справа: зависимость времени полуобесцвечивания от концентрации окислителя в растворе.

путь - перенос электрона на молекулу-окислитель, связанную с EGFP в составе единой полипептидной цепи. Для создания белков мы выбрали одноэлектронные (флаводоксин, малая субъединица бактериальной рибонуклеотид редуктазы) и двухэлектронные (моноаминоксидаза А, синий флуоресцентный белок бактерий) окислители белковой природы. Флаводоксины электронтранспортные белки бактерий (в данном случае E. coli), содержащие нековалентно связанную молекулу флавинмононуклеотида (ФМН) в качестве редокс-активного кофактора. Малая субъединица рибонуклеотид редуктазы первого класса из бактерии E. coli представляет собой гомодимер (так называемый R2), содержащий по два связанных атома железа в каждой из полипептидных цепей, т.е. всего 4 атома железа на гомодимер. Моноаминоксидаза А - митохондриальный фермент, содержащий ковалентно связанный флавинадениндинуклеотид (ФАД). Синий флуоресцентный белок бактерии Vibrio fischeri способен нековалентно связывать одну молекулу рибофлавина. Все четыре белка в естественном контексте являются участниками электрон-транспортных цепей, обеспечивающих клеточный метаболизм.

Форма с красной флуоресценцией, образующаяся в результате окислительной фотоконверсии (рис. 1), обладает крайне низкой фото- и химической стабильностью [1], поэтому не может быть использована для достоверной оценки эффективности фотоконверсии в различных условиях. Поэтому в качестве измеряемо- 
го экспериментального параметра было использовано фотообесцвечивание зеленой формы, сопровождающее первую стадию фотоконверсии.

Все варианты химерных белков, содержащие одноэлектронные белки-окислители, а именно флаводоксинEGFP, EGFP-флаводоксин, R2-EGFP, EGFP-R2, демонстрировали увеличенную по сравнению с EGFP скорость фотообесцвечивания. При этом в различных ориентациях (порядке полипептидных цепей) наблюдались незначительные отличия фотостабильности. Химерные белки флаводоксин-EGFP и R2-EGFP были охарактеризованы подробнее. В частности, мы охарактеризовали кинетики их фотообесцвечивания при добавлении в раствор сильного одноэлектронного акцептора, феррицианида калия. Оказалось, что характерное падение фотостабильности, наблюдаемое при увеличении концентрации феррицианида, у химерных белков выражено существенно сильнее, чем у EGFP (рис. 2).

Все варианты химерных белков, содержащие двухэлектронные белки-окислители, также показали увеличенную по сравнению с EGFP скорость фотообесцвечивания (рис. 3). Аналогично одноэлектронным белкамокислителям даже при добавлении феррицианида калия в больших концентрациях $(500 \mu \mathrm{M})$ химерные белки показывают меньшую фотостабильность по сравнению c EGFP. Таким образом, в случаях как одно-, так и двухэлектронных белков-окислителей эффективность переноса электрона возрастает.

\section{Заключение}

Созданы светоиндуцируемые искусственные электронтранспортные цепи (ЭТЦ) на основе EGFP. Следующие факты свидетельствуют в пользу работоспособности созданных ЭТЦ: ускоренное фотообесцвечивание без добавления внешних окислителей, снижение концентрационного порога чувствительности фотоконверсии/фотообесцвечивания к внешним окислителям.

Полагаем, что охарактеризованные нами ЭТЦ могут найти интересные варианты применения в современной микроскопии, в частности, в мультиплексной микроскопии, основанной на различиях в фотостабильности меток [12], микроскопии сверхвысокого разрешения, а также оптогенетике, группе методов оптического управления биохимическими процессами. Кроме того, ЭТЦ, аналогичные рассмотренным в данной работе, могли бы стать основой молекулярных флуоресцентных индикаторов окислительно-восстановительных процессов в клетке. Также эффективность переноса электрона между EGFP и белком-акцептором может быть использована для оценки расстояния между ними.

Исследование выполнено при финансовой поддержке РФФИ в рамках научного проекта № 17-00-00404 (17-00-00401).

\section{Список литературы}

[1] Bogdanov A.M., Mishin A.S., Yampolsky I.V., Belousov V.V., Chudakov D.M., Subach F.V., Verkhusha V.V., Lukyanov S., Lukyanov K.A. // Nat. Chem. Biol. 2009. V. 5. N 7. P. 459.

[2] Subach O.M., Patterson G.H., Ting L.-M., Wang Y., Condeelis J.S., Verkhusha V.V. // Nat. Methods. 2011. V. 8. N 9. P. 771.

[3] Saha R., Verma P.K., Rakshit S., Saha S., Mayor S., Pal S.K. // Sci. Rep. 2013. V. 3. P. 1580.

[4] Ai M., Mills H., Kanai M., Lai J., Deng J., Schreiter E., Looger L., Neubert T., Suh G. // PLoS One. 2015. V. 10. N 9. P. e0138127.

[5] Sattarzadeh A., Saberianfar R., Zipfel W.R., Menassa R., Hanson M.R. // Sci. Rep. 2015. V. 5. P. 11771.

[6] Bogdanov A.M., Acharya A., Titelmayer A.V., Mamontova A.V., Bravaya K.B., Kolomeisky A.B., Lukyanov K.A., Krylov A.I. // J. Am. Chem. Soc. 2016. V. 138. N 14. P. 4807.

[7] Acharya A., Bogdanov A.M., Grigorenko B.L., Bravaya K.B., Nemukhin A.V., Lukyanov K.A., Krylov A.I. // Chem. Rev. 2017. V. 117. N 2. P. 758.

[8] Byrdin M., Duan C., Bourgeois D., Brettel K. // J. Am. Chem. Soc. 2018. V. 140. N 8. P. 2897. doi $10.1021 /$ jacs.7b12755

[9] Bogdanov A.M., Bogdanova E.A., Chudakov D.M., Gorodnicheva T.V., Lukyanov S., Lukyanov K.A. // Nat. Methods. 2009. V. 6. N 12. P. 859.

[10] Bogdanov A.M., Kudryavtseva E.I., Lukyanov K.A. // PLoS One. 2012. V. 7. N 12. P. e53004.

[11] Mamontova A.V., Bogdanov A.M., Lukyanov K.A. // Biotechniques. 2015. V. 58. N 5. P. 258.

[12] Orth A., Ghosh R.N., Wilson E.R., Doughney T., Brown H., Reineck P., Thompson J.G., Gibson B.C. // Biomed. Opt. Express. 2018. V. 9. N 7. P. 2943. 